\title{
Total knee arthroplasty: improving outcomes with a multidisciplinary approach
}

This article was published in the following Dove Press journal: Journal of Multidisciplinary Healthcare

\section{James E Feng \\ David Novikov \\ Afshin A Anoushiravani Ran Schwarzkopf}

Division of Adult Reconstructive Surgery, NYU Langone Orthopedics, NYU Langone Health, New York, NY, USA
Correspondence: Ran Schwarzkopf Division of Adult Reconstructive Surgery, NYU Langone Orthopedics, NYU Langone Health, 30I East 17th Street, New York, NY 10003, USA

$\mathrm{Tel}+\mid \mathrm{I} 2 \mathrm{2} 5986000$

Email Ran.schwarzkopf@nyumc.org

\begin{abstract}
Total knee arthroplasty (TKA) is the most commonly performed inpatient surgical procedure within the USA and is estimated to reach 3.48 million procedures annually by 2030 . As value-based care initiatives continue to focus on hospital readmission rates and patient satisfaction, it has become essential for health care providers to develop and implement a multidisciplinary approach to enhance TKA outcomes while minimizing unnecessary expenditures. Through this necessity, clinical care pathways have been developed to standardize, organize, and improve the quality and efficiency of patient care while simultaneously encouraging the collaboration among various medical care providers. Here, we review several systems based programs and specialty care practices that can be adopted into the standard orthopedic practice. Keywords: perioperative optimization, clinical care pathways, adult reconstruction total joint replacement, perioperative orthopaedic surgical home, $\mathrm{POSH}$
\end{abstract}

\section{Introduction}

Osteoarthritis (OA) of the knee is one of the leading causes of disability among adults older than 65 years. ${ }^{1}$ Patients with OA experience significantly greater pain and functional deficits during normal daily activities, leading to a loss of productivity, ${ }^{2,3}$ and worsening quality of life. ${ }^{2,4}$ Although many conservative treatment modalities are available for the management of mild-to-moderate OA, end-stage arthritis of the knee is best managed with total knee arthroplasty (TKA). ${ }^{5}$

From 2005 to 2030, the number of TKA procedures is projected to exponentially rise by $601 \%$, reaching an estimated 3.48 million procedures annually. ${ }^{2}$ Even in its current state, TKA is the most commonly performed inpatient surgical procedure within the USA. ${ }^{3}$ As value-based care initiatives continue to focus on hospital readmission rates and patient satisfaction, it has become essential for health care providers to develop and implement a multidisciplinary approach to enhance TKA outcomes while minimizing unnecessary expenditures. Here, we review several systems based programs and specialty care practices that can be adopted into the standard orthopedic practice for a multidisciplinary approach to TKA.

\section{Methods}

A comprehensive literature review was performed using the PubMed, ScienceDirect, Google Scholar, and Scopus databases to identify potential review articles and studies for inclusion. Only articles that could be retrieved in the English language were included. All search results were initially reviewed by the first three authors (JEF, DN, 
and AAA) based on their title and abstract. Citations from the articles were further reviewed for potential inclusion.

\section{Clinical care pathways (CCPs)}

With the introduction of the Bundle Payments for Care Improvement (BPCI) initiative by the Centers for Medicare and Medicaid Services (CMS), CCPs have experienced a resurgence of interest over the past decade. ${ }^{4,6}$ CCPs are systematic tools, which standardize, organize, and improve the quality and efficiency of patient care. ${ }^{7}$ With respect to TKAs, adoption of CCPs has led to the increased utilization of multidisciplinary teams aimed at providing highly reliable levels of patient care, often involving primary care providers, inpatient specialists (ie, anesthesiology and critical care), and perioperative care experts (nursing, social work, physical therapy [PT], and occupational therapy [OT])., ${ }^{4,8}$ Numerous studies have reported that implementation of CCPs can improve patient-reported outcomes (PROs), promote early mobilization, and reduce lengths of stay (LOS). ${ }^{7,9-23}$ A study by Macario et $\mathrm{al}^{12}$ also demonstrated significant reductions in hospital costs after the implementation of a CCP. Approximately $54 \%$ of the cost reduction were due to reductions in operating room (OR) time and improved OR resource utilization. Decreases in LOS contributed an additional 15\% reduction in hospital costs. ${ }^{12}$ Total hospital cost variability, as measured by the coefficient of variation, also decreased from $28 \%$ to $18 \% .^{12}$ By reducing costs and cost variations, hospitals are better able to predict future resource utilization and allocation. Moreover, complication and readmission rates for venous thromboembolisms (VTEs), manipulation under anesthesia, wound infection, and stroke were reported to have decreased or remain unchanged. ${ }^{9,10}$

Arguably, these studies assessing the comparative effectiveness of CCPs are likely underestimating the beneficial effects of these pathways. Implementation of CCPs occurs at a systems level, and methods used for patients within a CCP likely carry over to all patients being treated within an institution, including those not partaking in a CCP. ${ }^{9,12}$ Taken together, CCPs in TKA are proven methods for maximizing patient outcomes while improving hospital efficiency. ${ }^{12}$

\section{Preoperative education}

Preoperative patient education (PPE) programs are designed to improve patient compliance and outcomes through the education of proper self-care, rehabilitation, as well as setting realistic expectations by a variety of health care specialists including psychologists, physiotherapists, and physicians. ${ }^{24}$ Several cohort studies have demonstrated that PPEs may decrease LOS and the incidence of falls in the immediate postoperative period. ${ }^{25,26}$ In a study by Clarke et al, ${ }^{27} \mathrm{PPE}$ also increased the likelihood of spinal anesthesia over general anesthesia. However, randomized control trials, systematic reviews, and meta-analyses have failed to show consistent improvements in validated PRO scores, patient anxiety, LOS, functional outcomes, or complication rates. ${ }^{24,28-31}$ This discrepancy is likely due to the large amount of heterogeneity seen with PPE sessions, duration, and time of administration between institutions. As such, we believe that PPE continues to be a valuable resource for patients and physicians alike. ${ }^{32}$

\section{Preadmission testing (PAT)}

Originally described by Crosby et $\mathrm{al}^{33}$ in 1972 , dedicated PAT clinics were developed to minimize inpatient LOS, reduce same day cancellations, and ensure that patients had been properly optimized prior to the day of surgery. ${ }^{34}$ Today, PAT clinics are collaborative settings whereby patients may be examined and medically optimized by a multidisciplinary team of health care providers. ${ }^{35}$ In an audit loop study by Kamal et al, ${ }^{36}$ patients undergoing total joint arthroplasty (TJA) reported a significant 5\% decrease in mortality, 50\% reduction in unplanned Post-Anesthesia Care Unit (PACU) admissions, $60 \%$ reduction in unplanned admissions to the Intensive Care Unit (ICU), a half-day decrease in LOS in the sub-critical unit, and a 0.6 day decrease in LOS in the ICU following the implementation of a dedicated PAT clinic. Other studies have reported that the introduction of a dedicated PAT clinic can lead to a $38 \%-66 \%$ reduction in patient no-shows and medically related cancellations. ${ }^{37-39}$ Patients referred to PAT also benefit from integrated perioperative medical management protocols, such as alterations in $\beta$ blockade, angiotensin-converting enzyme inhibitors (ACEIs), and anticoagulation therapy preoperatively. ${ }^{40}$ Additionally, the prevention of cancellations through PAT clinic reduces the associated frustration and anxiety experienced by both patient and hospital staff. For many, the upfront costs of developing a PAT clinic may act as a significant barrier. However, longterm benefits to patient safety make a clear argument for an integrated PAT pathway for all TKA patients.

\section{Cardiac optimization and VTE prophylaxis}

Despite major advancements in the medical management of cardiovascular disease (CVD), cardiovascular complications continue to be a significant source of postoperative morbidity and mortality. ${ }^{41}$ In large cohort and randomized studies, perioperative myocardial infarction occurs in up to $6.2 \%$ of 
noncardiac surgeries. ${ }^{41}$ In a recent study of patients undergoing TJA by Bass et al, ${ }^{42}$ high-sensitivity cardiac troponin $\mathrm{T}$ was found to be elevated in $13.5 \%$ patients on postoperative day 2 . Of these patients, only $0.77 \%$ report clinical symptoms, suggesting that the incidence of myocardial injury may significantly be underreported. Asymptomatic myocardial infarctions can predispose to further cardiac morbidity and mortality, highlighting the importance of systematic preoperative cardiovascular risk evaluation and optimization prior to TKA through a multidisciplinary approach. ${ }^{42,43}$ For patients with pre-existing or newly diagnosed CVD, hypertension, or dyslipidemia, a comprehensive review and adjustment of cardiac medications by the patient's primary care provider or cardiologist improves perioperative outcomes. In addition, proper patient counseling can help with the informed decision-making process and assists in aligning patient-physician expectations. ${ }^{42}$

\section{Medical management}

With a prevalence of $\sim 30 \%$ among American adults older than 18 years, and $>65 \%$ by the age of 60 years, hypertension is a common comorbid condition in the orthopedist's clinic. ${ }^{44}$ Several recent studies have demonstrated that for patients receiving $\beta$ blockers, continuing its use throughout the perioperative period reduces the incidence of acute myocardial infarction (MIs) ( $0.31 \%$ vs $0.22 \%)$, stroke $(0.07 \%$ vs $0.04 \% ; P=0.05)$, and overall risk of mortality $(0.14 \%$ vs $0.07 \%$ ) but increases the incidence of intraoperative hypotension $(0.8 \%$ vs $1.7 \%) .{ }^{45}$ As a result, the current American College of Cardiology (ACC), American Heart Association (ACA), and Surgical Care Improvement Project (SCIP) guidelines recommend patients on chronic $\beta$ blocker therapy to continue its use perioperatively. ${ }^{45,46}$ However, for patients with a Revised Cardiac Risk Index (RCRI) score of $\geq 3$ (risk factors include diabetes, heart failure, CAD, renal insufficiency, and cerebrovascular accident) or newly diagnosed ischemic heart disease requiring $\beta$ blockers, adequate lead time of 2-7 days should be provided for the cardiologist to properly assess the patient's tolerance to the drug. ${ }^{26}$ Meanwhile, ACEIs and angiotensin receptor blockers (ARBs) should be discontinued on the day of surgery and restarted in the immediate postoperative period once the patient is euvolemic. Several studies have demonstrated an increased incidence of postinduction hypotension (OR 1.93-5.8), postoperative acute kidney injury (AKI; OR 2.68), LOS (3.3 vs 5.8), and use of ephedrine (OR 3.2). ${ }^{47,48}$

Similar to hypertensive disease, hyperlipidemia has now been reported to affect $\sim 31.7 \%$ of US adults, with $\sim 48.1 \%$ of patients receiving proper care. ${ }^{44,49}$ Statins are effective lipid-lowering agents used to modify long-term cardiac risk factors in patients afflicted by hyperlipidemia. ${ }^{50}$ Moreover, the use of statins throughout the perioperative period has demonstrated favorable outcomes in noncardiac surgery patients. Several large cohort meta-analyses have proven that statins significantly reduce the risk for mortality (RR $0.50)$ and $\mathrm{MI}$ (RR 0.53) in the immediate postoperative period. ${ }^{51-53}$ More interestingly, a 10-year, retrospective study demonstrated a sizable reduction for revision total hip arthroplasty (THA) due to aseptic loosening (RR 0.36). ${ }^{54}$ However, follow-up studies have reported that these results may be due to flawed study designs. ${ }^{54,55}$ In summary, current recommendations state that statins should be continued preoperatively in patients currently taking statins and undergoing noncardiac surgery. ${ }^{46,51}$ For statin naive patients, we recommended starting statin therapy $1-2$ weeks prior to TJA. ${ }^{51}$

\section{Cardiac coronary stents}

Cardiac coronary intervention may increase the morbidity and mortality associated with elective TKA. Patients undergoing TKA within 6 months of percutaneous coronary intervention (PCI) with stenting may be at increased risk of stent thrombosis. ${ }^{56,57}$ TJA should be delayed for a minimum of 6 months after a bare metal stent and 12 months after a drug eluting stent. ${ }^{58}$ For patients with stents who are eligible for surgery, dual antiplatelet therapy (DAPT) should be discontinued prior to TJA. Current evidence indicates that continuation of DAPT in the perioperative period substantially increased the risk for severe bleeding without a decreased incidence for major cardiac events. ${ }^{58}$

\section{VTE prevention}

VTEs are one of the most common causes of 90-day readmissions for TJA. ${ }^{59}$ Current VTE prevention recommendations aim to decrease a patient's LOS and hospital's financial burden by balancing adequate VTE prevention against the risks of hematoma development, wound drainage, and infection. ${ }^{60} \mathrm{In}$ patients who are appropriately risk stratified, the use of aspirin lowers the rate of periprosthetic joint infection, bleeding, and wound drainage, reduces hospital costs, and simplifies drug administration and monitoring. ${ }^{61}$ The American Academy of Orthopaedic Surgeons (AAOS) also recommends the use of mechanical compression devices (MCD) in combination with aspirin..$^{62} \mathrm{~A}$ randomized control trial examining the effects of 6 weeks of MCD in patients receiving $325 \mathrm{mg}$ aspirin twice daily for 3 weeks demonstrated a significantly lower incidence 
of deep vein thrombosis (DVT) ( 0 vs 23.1\%) for patients with MCD than without. ${ }^{63}$

In summary, deciding on a suitable prophylactic therapy to achieve the optimal balance of VTE and bleeding prevention necessitates an individualized evaluation of the patient's risk profile. Comorbidities such as blood clotting disorders, obesity (body mass index [BMI] $>30 \mathrm{~kg} / \mathrm{m}^{2}$ ), chronic obstructive pulmonary disease (COPD), history of DVT/ pulmonary embolism (PE), stroke, metastatic cancer, sepsis, anemia, depression, and atrial fibrillation place the patient at an elevated risk for developing symptomatic PE. ${ }^{64}$ Studies are currently ongoing to assess the best thromboprophylaxis based on a patient's risk profile.

\section{Anesthesia considerations and pain management}

Anesthesia and postoperative pain management is critical for the delivery of high-quality and efficient orthopedic care. Anesthesiologists are charged with the task of medically managing the patient perioperatively while also employing prophylactic measures aimed at curbing the following four common postoperative events: volume depletion, blood loss, pain, and nausea. ${ }^{65}$

Current operative protocols at many medical centers require that patients remain nil per os the night before surgery, resulting in perioperative volume depletion. Current evidence suggests that early and aggressive volume status optimization preoperatively can act as a prophylactic measure for postoperative hemodynamic fluctuations, nausea, and vomiting and improves patient satisfaction while reducing LOS. ${ }^{65}$ Current guidelines outlined by the American Society of Anesthesiologists (ASA) also indicate that clear fluid consumption 2 hours preoperatively does not increase the risk for intraoperative aspiration. ${ }^{66}$ Moreover, oral volume enhancement with carbohydrates prior to surgery can decrease postoperative nausea and vomiting (PONV) and may prevent hypotensive episodes. ${ }^{67}$ As oral fluid hydration provides greater hemodynamic stability among elderly TJA candidates, the risk for advanced medical interventions and intensive care consultation is reduced.

Over the last decade, the widespread utilization of tranexamic acid (TXA), an inexpensive antifibrinolytic, has been shown to substantially reduce postoperative blood loss. Sukeik et al ${ }^{68}$ critically evaluated the literature and reported that preoperative or prolonged IV administration of TXA in THA led to a $20 \%$ reduction in blood transfusions. Complication profiles including clinically significant VTE events and infections remained unchanged. In addition, decreased post- operative blood loss, wound drainage, and hematoma development further promotes rapid rehabilitation following TJA. ${ }^{69}$

Multimodal pain management is essential for favorable short- and long-term outcomes following TJA. Robust perioperative pain management programs minimizing opioid administration while emphasizing a multitargeted approach have been shown to promote postoperative rehabilitation and reduce LOS..$^{70,71}$ Perioperative analgesics should emphasize a variety of drug classes such as non-steroidal antiinflammatory drugs, acetaminophen, long-acting opioids, ketamine, and/or gabapentin. ${ }^{65,71}$ Neuraxial and peripheral blocks, including spinal and adductor blockades, are effective at controlling acute postoperative pain following TJA. Compared to general anesthesia, spinal blockade has also demonstrated significant reductions in VTE, overall complications rates, 30-day mortality rates, LOS, bleeding, and perioperative opioid usage. ${ }^{72}$ Periarticular injection cocktails with both short- and long-acting agents injected into the joint and surrounding soft tissues have also been shown to reduce pain levels. ${ }^{73-75}$ Implementation of multimodal pain control eliminates the need for patient-controlled analgesia (PCA) devices, which have been shown to prolong LOS, increase patient morbidity, and prevent early rehabilitation. ${ }^{7-76}$ Despite reduced narcotic intake, PONV still remains a preoperative challenge and may be more intimately associated with hemodynamic status. The proactive use of antiemetics and glucocorticoids prior to anesthesia can effectively reduce postoperative morbidity and improve recovery.

\section{Dietary weight loss and bariatric surgery}

Obese patients are at increased risked for intraoperative and postoperative TKA complications. The complications include MI, stroke, component malpositioning, readmission rate, incidence of revision surgery, rate of postoperative infections, functional outcomes, overall complication rate, and 10-year survival rate. ${ }^{77-83}$ Financially, Kremers et al 84 found for every $5 \mathrm{U}$ increase in BMI $>30 \mathrm{~kg} / \mathrm{m} 2$, hospital costs for primary TKA are increased by $\$ 250-\$ 300$ due to the associated complications. Weight loss initiatives have, therefore, gained favor by the orthopedic community, with the AAOS recent guideline update promoting weight loss for all patients with BMI $>25 \mathrm{~kg} / \mathrm{m}^{2}{ }^{25}$ Additionally, due to the increased risk of surgical complications, many institutions have placed a hard stop on TKA candidates with BMI $>40 \mathrm{~kg} / \mathrm{m}^{2} .{ }^{86}$ However, weight loss in the obese population remains a challenge for both the patient and the physician. Conservative, nonsurgical weight loss interventions, including dietary restriction and 
exercise, have been proven to produce significant weight loss in obese patients. The process of weight loss through diet and exercise can also lead to self-reported improvement in walking distance, stair climbing, pain, and disability. ${ }^{87}$ Furthermore, patients with dietician-led weight management prior to TKA may benefit from continued weight loss 1 year following TJA ${ }^{88}$ Recent studies have also shown promising results from medically supervised, very low-calorie diets (VLCD) with high-protein supplements. ${ }^{89}$ For patients who are unable to lose weight with diet and exercise, bariatric surgery should be considered.

Bariatric surgery has proven to be an effective and safe weight loss modality with mortality rates as low as $0.1 \%{ }^{86,90}$ Several studies have demonstrated that patients who undergo bariatric surgery prior to TKA show superior improvements in physical function, stiffness, knee pain, wound infection, and readmission rates post-TKA. ${ }^{82,86,91,92}$ Despite these positive findings, other studies have remained equivocal..$^{93}$ One study by Martin et $\mathrm{al}^{94}$ has even reported an increased risk for revision surgery in patients with staged bariatric surgery. This discrepancy in outcomes may be explained by a propensity for malnutrition and a persistent catabolic state for 2 years following bariatric surgery. ${ }^{95,96}$ Bariatric surgery should therefore be assessed on a case-by-case basis.

\section{Physical therapy}

During the immediate postoperative period, patients continue to experience weakness and impairments in functional performance following TKA. ${ }^{97}$ Functional performance worsens 20\%-25\% (1 month) following TKA along with deficits in knee extension strength as large as 35\% (1-2 years) following TKA. ${ }^{98,99}$ Absence of a standardized rehabilitation regimen and program among providers has caused low enrollment in postoperative rehabilitation programs, with reports showing a participation level of $26 \%$, varying by institution and surgeon preference. ${ }^{100}$ While there is a paucity of conclusive data supporting the use of a structured rehabilitation or PT program, studies have generally been positive with some reports demonstrating improved functional performance 1 year following TKA in patients enrolled in an exercise rehabilitation program and others report improvements in joint ROM and the quality of life 3-4 months postoperatively. ${ }^{99,101}$

Outpatient PT regimens employing strengthening and functional exercises under the guidance of a trained physical therapist have been shown to provide the best outcomes as they allow a more individualized approach to treatment. ${ }^{100}$ While other studies have found that postacute exercise programs failed to reduce knee pain and activity limitations
1 year after TKA, the authors note that only $50 \%$ of participants were able to complete the full 16-class program, with time constraints being reported as a major limitation for patients. ${ }^{102}$ Accessibility to health care may therefore be a barrier to optimal care. A plausible solution involving telerehabilitation technology for patients struggling to adhere to PT programs has been recently introduced. Using videoconferencing and prerecorded instructional videos, physical therapists can observe and guide patients in completing various exercises from the comfort of their home. Preliminary results show that this type of $\mathrm{PT}$ is noninferior to those that involve face-to-face interactions. ${ }^{103-105}$ As the technology is new, further evaluation is required to assess the effectiveness of this treatment modality.

\section{Shared decision making (SDM) and patient activation}

SDM is a collaborative process between patients and physicians that helps develop an ideal treatment and care plan aligning with the clinical goals and values of the patient. SDM models have been used with increasing frequency as the CMS continues to advocate for medical initiatives that promote patient-centered care. A recent systematic review demonstrated that patients who had SDM aids integrated into their care not only played a more active role in their treatment plan but were also more likely to receive care aligning with their personal goals. ${ }^{106}$ In addition, patients who engage in SDM typically opt for less invasive interventions, reducing the morbidity and mortality associated with the management of chronic diseases. When executed in accordance with the guidelines set by the Institute of Medicine (IOM), physicians and patients can expect reduced hospital expenditures while significantly improving treatment plan adherence and enhancing functional and PROs. ${ }^{107}$

A major barrier to the widespread implementation of the SDM principles is patient activation, or more simply, the active participation of patients in their medical optimization throughout their perioperative course. The importance of patient activation is paramount within the perioperative setting, an environment that is highly dependent on the degree of patient-directed interventions including PT and OT. In a study by Andrawis et al, ${ }^{108}$ TJA recipients with greater preoperative involvement achieved improved pain relief, resulting in higher patient satisfaction scores following surgery.

\section{SDM in total joint arthroplasty}

SDM requires the effective delivery of accurate, clinically relevant information, presented in a format that the public 
can understand. The presented information must describe the basic disease state, procedure, as well as relevant risks and benefits associated with the intervention. Additionally, the information should be presented in an interactive manner allowing patients to make informed decisions aligning with their personal values.

In an effort to objectively present risk factors associated with specific interventions, physicians have utilized risk stratification instruments when engaging in SDM discussions. Although several of these instruments are readily collected (eg, Charlson Comorbidity Index [CCI] and ASA score), these instruments can be difficult to interpret in a clinically meaningful manner. ${ }^{109,110}$ Thus, it is critical that preoperative screening instruments be clinically relevant and interpretable to patients. In response, the Readmission Risk Assessment Tool and American Joint Replacement Registry (AJRR) Total Joint Risk Calculator were developed by the AAOS in an effort to more precisely calculate an individual's risk profile when undergoing TJA. ${ }^{11,112}$ Risk calculators, such as AJRR Total Joint Risk Calculator, may provide clinicians with the resources necessary to improve health care transparency, while enhancing the patient-physician relationship. In addition, these tools provide patients with the baseline metric that they need to initiate risk reductive behaviors. Most importantly, health benefits achieved during the preoperative optimization period can provide the patient with the foundation for long-term healthy living.

\section{Clinical efficacy of SDM}

Several studies have evaluated the clinical efficacy of SDM following orthopedic procedures. In a landmark study by Bozic et al, ${ }^{113}$ patients were randomized to a SDM cohort consisting of digital videos and booklets or a control cohort receiving the surgeons' standard of care. Patients within the SDM cohort reported improvements in informed decision making, confidence, and satisfaction. A separate study by Sepucha et $\mathrm{al}^{114}$ demonstrated that orthopedic patients who met SDM criteria had significantly higher disease-specific and overall quality of life. Moreover, patients who participated in the SDM model were less likely to regret their selected treatment modality and had higher self-reported satisfaction scores. ${ }^{115}$

Despite these positive outcomes, several barriers may preclude physicians and hospitals from implementing a SDM model. Substantial costs associated with designing and implementing decision-making aids (eg, digital video disks, pamphlets, and electronic applications) can be prohibitive, particularly within a small specialty practice. Moreover, many of the available SDM instruments require continuous collection of patient-reported metrics in a systematic and organized manner. Such a process often necessitates institutions with advanced electronic medical record (EMR) systems, further straining resources. ${ }^{116}$ In spite of the challenges, patients participating in SDM are more likely to select conservative interventions and are more invested in modifying their risk factors prior to surgery, effectively reducing health care costs and improving outcomes. ${ }^{106,117,118}$

\section{Innovative approaches at implementing SDM}

Over the past decade, modern technologies that take advantage of web-based platforms and wearable devices have helped connect patients with their care teams. These applications provide both patients and physicians with tools that can monitor a multitude of clinical metrics. The implementation of sensors in wearable devices including tactile, heart rate, and pulse oximetry sensors, in combination with scheduled administration of questionnaires, may also assist health care providers by alerting clinicians of poor patient rehabilitation progress. Through these innovative tools and integration of real-time data, orthopedic surgeons can remotely provide feedback to patients, ensure that clinical goals are achieved, maximize patient autonomy, and strengthen the physician-patient relationship. While several preliminary studies have demonstrated that web-based electronic rehabilitation programs can be noninferior in providing postoperative rehabilitative care, further studies are needed to evaluate which of these tools may be best suited for the standard orthopedic practice and how these tools can be implemented systematically across a diverse spectrum of clinical practices. ${ }^{104,105}$

\section{Dependence and psychiatric issues}

Outcomes following TKA are highly influenced by the degree of patient-directed involvement, including participation in programs such as PT/OT. TKA candidates who are motivated, knowledgeable, and willing to adjust their behavior can achieve better outcomes as they become an integral member of the health care team. This higher level of patient activation ultimately results in improved reported outcomes postoperatively. ${ }^{108}$ Studies have also shown that the presence of psychiatric conditions can negatively impact recovery following TKA as they may preclude patient activation. ${ }^{119-122}$

In a large retrospective study, Singh and Lewallen ${ }^{123}$ reported that patients undergoing TKA with a concomitant diagnosis of anxiety had higher knee pain scores at 2 (OR 1.4) and 5 years (OR 1.9) postoperatively. It was also dem- 
onstrated that patients diagnosed with depression had similar suboptimal pain scores at 5 years postoperatively (OR 1.7). ${ }^{123}$ Depression, anxiety, and perceived disability can therefore negatively impact preoperative mental health scores in TKA patients, predisposing these patients to a lower quality of life following TKA. ${ }^{124-126}$ Moreover, pain catastrophizing, the exaggeration of pain severity and belief that one is helpless in controlling it, is a predictor of poor outcomes following TKA with studies showing that these patients benefit from a patient-centered approach emphasizing various behavioral pain-coping interventions. This includes patient counseling and patient-specific intervention protocols, such as cognitive behavioral therapy (CBT). ${ }^{127-129}$ Preoperative substance abuse and illicit drug use have also been shown to negatively impact postoperative outcomes as it is associated with increased pain scores, longer LOS, and other perioperative complications, including infection and VTEs. ${ }^{125,130-132}$

Prior to TKA, patients should be screened using validated and reliable instruments such as the AUDIT- $\mathrm{C}^{133}$ for alcohol abuse and dependence, the DAST- $10^{134}$ for drug abuse, the PHQ-2 ${ }^{135}$ for depression, and the GAD- $7^{136}$ for anxiety. A high score on any of these screening tools warrants further evaluation by a mental health expert, and surgery should be delayed until a formal diagnosis and treatment plan has been made. Management of psychiatric disorders includes a course of medication and/or psychotherapy. A preoperative CBT program can address psychiatric risk factors by providing accurate information to the patient, setting realistic expectations, modifying negative thoughts, and teaching meditation/ relaxation with guided imagery. ${ }^{28,137-139}$

Active illicit drug abuse is an absolute contraindication to surgery, and patients should be referred to an appropriate drug rehabilitation center prior to even considering surgery. ${ }^{140}$ Surgery should only be considered if there is a documented 1 year period of illicit drug use abstinence as shorter durations have been correlated with a higher rate of drug relapse and septic failure. ${ }^{140}$

\section{Conclusion}

With a greater emphasis on reducing hospital LOS, rehabilitation services are becoming increasingly utilized. Shifting from a primarily medical service, rehabilitation is now a multidisciplinary effort involving various health care teams including physical and occupational therapists. Patients treated by such teams reported improvements in outcome measures and high satisfaction with their care, owing to the organization, ease of communication, and availability of health care professionals. ${ }^{141}$ The implementation of a multidisciplinary approach to patient care can therefore provide significant fiscal and clinical benefits.

\section{Disclosure}

The authors report no conflicts of interest in this work.

\section{References}

1. Neogi T. The epidemiology and impact of pain in osteoarthritis. Osteoarthritis Cartilage. 2013;21(9):1145-1153.

2. Kurtz S, Ong K, Lau E, Mowat F, Halpern M. Projections of primary and revision hip and knee arthroplasty in the United States from 2005 to 2030. J Bone Joint Surg. 2007;89(4):780-785.

3. Fingar KR, Stocks C, Weiss AJ, Steiner CA [webpage on the Internet]. Most Frequent Operating Room Procedures Performed in U.S. Hospitals. In: HCUP Statistical Brief \# 186. Agency for Healthcare Research and Quality (US); 2014:1-15. Available from: http://www. ncbi.nlm.nih.gov/pubmed/25695123. Accessed June 13, 2017.

4. Sayeed Z, El-Othmani MM, Anoushiravani AA, Chambers MC, Saleh KJ. Planning, building, and maintaining a successful musculoskeletal service line. Orthop Clin North Am. 2016;47(4):681-688.

5. Jüni P, Reichenbach S, Dieppe P. Osteoarthritis: rational approach to treating the individual. Best Pract Res Clin Rheumatol. 2006;20(4): 721-740.

6. Anoushiravani AA, Iorio R. Alternative payment models: from bundled payments for care improvement and comprehensive care for joint replacement to the future? Semin Arthroplasty. 2016;27(3):151-162.

7. Barbieri A, Vanhaecht $K$, Van Herck P, et al. Effects of clinical pathways in the joint replacement: a meta-analysis. BMC Med. 2009;7(1):32.

8. Kee JR, Edwards PK, Barnes CL. Effect of risk acceptance for bundled care payments on clinical outcomes in a high-volume total joint arthroplasty practice after implementation of a standardized clinical pathway. J Arthroplasty. 2017;32(8):2332-2338.

9. Gooch K, Marshall DA, Faris PD, et al. Comparative effectiveness of alternative clinical pathways for primary hip and knee joint replacement patients: a pragmatic randomized, controlled trial. Osteoarthritis Cartilage. 2012;20(10):1086-1094.

10. Halliwell D. A clinical pathway reduced length of stay, time to ambulation, and complications after hip and knee arthroplasty. Evid Based Nurs. 1999;2(4):123-123.

11. Katz J, Martin T. Clinical pathways and the commodification of total joint replacement. Osteoarthritis Cartilage. 2012;20(10):1057-1058.

12. Macario A, Horne M, Goodman S, et al. The effect of a perioperative clinical pathway for knee replacement surgery on hospital costs. Anesth Analg. 1998;86(5):978-984.

13. Van Herck P, Vanhaecht K, Deneckere S, et al. Key interventions and outcomes in joint arthroplasty clinical pathways: a systematic review. J Eval Clin Pract. 2010;16(1):39-49.

14. Phan DL, Ahn K, Rinehart JB, Calderon M-D, Wu W-D, Schwarzkopf R. Joint arthroplasty Perioperative Surgical Home: impact of patient characteristics on postoperative outcomes. World J Orthop. 2016;7(6):376-382.

15. Iwuchukwu C, Wright D, Sofine A, Schwarzkopf R [homepage on the Internet]. An Original Study Can a Total Knee Arthroplasty Perioperative Surgical Home Close the Gap Between Primary and Revision TKA Outcomes?. 2016. Available from: www.amjorthopedics.com. Accessed November 1, 2017.

16. Kain ZN, Vakharia S, Garson L, et al. The perioperative surgical home as a future perioperative practice model. Anesth Analg. 2014;118(5):1126-1130.

17. Garson L, Schwarzkopf R, Vakharia S, et al. Implementation of a total joint replacement-focused. Anesth Analg. 2014;118(5):1081-1089.

18. Cyriac J, Garson L, Schwarzkopf R, et al. Total joint replacement perioperative surgical home program: 2-year follow-up. Anesth Analg. 2016;123(1):51-62. 
19. Raphael DR, Cannesson M, Schwarzkopf R, et al. Total joint Perioperative Surgical Home: an observational financial review. Perioper Med (Lond). 2014;3:6.

20. Alem N, Rinehart J, Lee B, et al. A case management report: a collaborative perioperative surgical home paradigm and the reduction of total joint arthroplasty readmissions. Perioper Med (Lond). 2016;5(1):27.

21. Chaurasia A, Garson L, Kain ZL, Schwarzkopf R. Outcomes of a joint replacement surgical home model clinical pathway. Biomed Res Int. 2014;2014:296302.

22. Behery OA, Kester BS, Williams J, et al. Patterns of ninety-day readmissions following total joint replacement in a bundled payment initiative. J Arthroplasty. 2017;32(4):1080-1084.

23. Schwarzkopf R, Snir N, Sharfman ZT, et al. Effects of modification of pain protocol on incidence of post operative nausea and vomiting. Open Orthop J. 2016;10:505-511.

24. Wallis JA, Taylor NF. Pre-operative interventions (non-surgical and non-pharmacological) for patients with hip or knee osteoarthritis awaiting joint replacement surgery - a systematic review and metaanalysis. Osteoarthritis Cartilage. 2011;19(12):1381-1395.

25. Yoon RS, Nellans KW, Geller JA, Kim AD, Jacobs MR, Macaulay W. Patient education before hip or knee arthroplasty lowers length of stay. J Arthroplasty. 2010;25(4):547-551.

26. Elkassabany NM, Abraham D, Huang S, et al. Patient education and anesthesia choice for total knee arthroplasty. Patient Educ Couns. 2017;100(9):1709-1713.

27. Clarke HD, Timm VL, Goldberg BR, Hattrup SJ. Preoperative patient education reduces in-hospital falls after total knee arthroplasty. Clin Orthop Relat Res. 2012;470(1):244-249.

28. Mcdonald S, Mj P, Beringer K, et al. Preoperative education for hip or knee replacement (review). Cochrane Database Syst Rev. 2014;5:CD003526.

29. Aydin D, Klit J, Jacobsen S, Troelsen A, Husted H. No major effects of preoperative education in patients undergoing hip or knee replacement - a systematic review. Dan Med J. 2015;62(7):A5106.

30. Jordan RW, Smith NA, Chahal GS, Casson C, Reed MR, Sprowson AP. Enhanced education and physiotherapy before knee replacement; is it worth it? A systematic review. Physiotherapy. 2014;100(4):305-312.

31. Moulton LS, Evans PA, Starks I, Smith T. Preoperative education prior to elective knee arthroplasty surgery does not change patient outcomes. Musculoskeletal Care. 2017;15(4):341-344.

32. Kim K, Chin G, Moore T, Schwarzkopf R. Does a preoperative educational class increase patient compliance. Geriatr Orthop Surg Rehabil. 2015;6(3):153-156.

33. Crosby DL, Griffith GH, Jenkins JR, Real R, Roberts BC, Forrest AP. General surgical pre-admission clinic. Br Med J. 1972;3(5819): 157-159.

34. Malkin KF. Patients' perceptions of a pre-admission clinic. J Nurs Manag. 2000;8(2):107-113.

35. Fellows H, Lucas B, Burgess L, Abbott D, Clare A, Barton K. Orthopaedic pre-admission assessment clinics: part I. J Orthop Nurs. 1998;2(4):209-218.

36. Kamal T, Conway RM, Littlejohn I, Ricketts D. The role of a multidisciplinary pre-assessment clinic in reducing mortality after complex orthopaedic surgery. Ann R Coll Surg Engl. 2011;93(2):149-151.

37. McKendrick DA, Cumming G, Lee A. A 5-year observational study of cancellations in the operating room: does the introduction of preoperative preparation have an impact? Saudi J Anaesth. 2014;8(5):8.

38. Conway JB, Goldberg J, Chung F. Preadmission anaesthesia consultation clinic. Can J Anaesth. 1992;39(10):1051-1057.

39. Knox M, Myers E, Hurley M. The impact of pre-operative assessment clinics on elective surgical case cancellations. Surgeon. 2009;7(2):76-78.

40. Correll DJ, Bader AM, Hull MW, Hsu C, Tsen LC, Hepner DL. Value of preoperative clinic visits in identifying issues with potential impact on operating room efficiency. Anesthesiology. 2006;105(6):1254-1259.

41. Smilowitz NR, Berger JS. Perioperative management to reduce cardiovascular events. Circulation. 2016;133(11):1125-1130.
42. Bass AR, Rodriguez T, Hyun G, et al. Myocardial ischaemia after hip and knee arthroplasty: incidence and risk factors. Int Orthop. 2015;39(10):2011-2016.

43. Mangano DT, Browner WS, Hollenberg M, et al. Long-term cardiac prognosis following noncardiac surgery. JAMA. 1992;268(2):233.

44. Nwankwo T, Yoon SS, Burt V, Gu Q. Hypertension among adults in the United States: National Health and Nutrition Examination Survey, 2011-2012. NCHS Data Brief. 2013;133:1-8.

45. Bemenderfer TB, Rozario NL, Moore CG, Karunakar MA. Morbidity and mortality in elective total knee arthroplasty following surgical care improvement project guidelines. J Arthroplasty. 2016;31(9):202-206.

46. Fleisher LA, Fleischmann KE, Auerbach AD, et al. 2014 ACC/AHA guideline on perioperative cardiovascular evaluation and management of patients undergoing noncardiac surgery: executive summary. $\mathrm{J} \mathrm{Nucl}$ Cardiol. 2015;22(1):162-215.

47. Nielson E, Hennrikus E, Lehman E, Mets B. Angiotensin axis blockade, hypotension, and acute kidney injury in elective major orthopedic surgery. J Hosp Med. 2014;9(5):283-288.

48. Calloway JJ, Memtsoudis SG, Krauser DG, Ma Y, Russell LA, Goodman SM. Hemodynamic effects of angiotensin inhibitors in elderly hypertensives undergoing total knee arthroplasty under regional anesthesia. J Am Soc Hypertens. 2014;8(9):644-651.

49. Mozaffarian D, Benjamin EJ, Go AS, et al. Heart disease and stroke statistics-2015 update : a report from the American Heart Association. Circulation. 2015;131(4):e29-e39.

50. Bibbins-Domingo K, Grossman DC, Curry SJ, et al. Statin use for the primary prevention of cardiovascular disease in adults. JAMA. 2016;316(19):1997.

51. De Waal BA, Buise MP, Van Zundert AAJ. Perioperative statin therapy in patients at high risk for cardiovascular morbidity undergoing surgery: a review. Br J Anaesth. 2014;114(1):44-52.

52. Chaitman BR, Bourassa MG, Davis K, et al. Angiographic prevalence of high-risk coronary artery disease in patient subsets (CASS). Circulation. 1981;64(2):360-367.

53. Raju MG, Pachika A, Punnam SR, et al. Statin therapy in the reduction of cardiovascular events in patients undergoing intermediate-risk noncardiac, nonvascular surgery. Clin Cardiol. 2013;36(8):456-461.

54. Thillemann TM, Pedersen AB, Mehnert F, et al. The risk of revision after primary total hip arthroplasty among statin users. J Bone Joint Surg Am. 2010;92(5):1063-1072.

55. Lalmohamed A, Van Staa TP, Vestergaard P, et al. Statins and risk of lower limb revision surgery: the influence of differences in study design using electronic health records from the United Kingdom and Denmark. Am J Epidemiol. 2016;184(1):58-66.

56. Hawn MT, Graham LA, Richman JS, Itani KMF, Henderson WG, Maddox TM. Risk of major adverse cardiac events following noncardiac surgery in patients with coronary stents. JAMA. 2013;310(14):1462.

57. Auerbach A. Assessing and reducing the cardiac risk of noncardiac surgery. Circulation. 2006;113(10):1361-1376.

58. van Kuijk J-P, Flu W-J, Schouten O, et al. Timing of noncardiac surgery after coronary artery stenting with bare metal or drug-eluting stents. Am J Cardiol. 2009;104(9):1229-1234.

59. Pellegrini VD, Donaldson CT, Farber DC, Lehman EB, Evarts CM. The mark coventry award: prevention of readmission for venous thromboembolism after total knee arthroplasty. Clin Orthop Relat Res. 2006;452:21-27.

60. Parvizi J, Huang R, Restrepo C, et al. Low-dose aspirin is effective chemoprophylaxis against clinically important venous thromboembolism following total joint arthroplasty. J Bone Joint Surg. 2017;99(2): 91-98.

61. Parvizi J, Ceylan HH, Kucukdurmaz F, Merli G, Tuncay I, Beverland D. Venous thromboembolism following hip and knee arthroplasty: the role of aspirin. J Bone Joint Surg Am. 2017;99(11):961-972.

62. Mont M, Jacobs J, Lieberman J, et al. Preventing venous thromboembolic disease in patients undergoing elective total hip and knee arthroplasty. J Bone Joint Surg Am . 2012;94(8):673-674. 
63. Snyder MA, Sympson AN, Scheuerman CM, Gregg JL, Hussain LR. Efficacy in deep vein thrombosis prevention with extended mechanical compression device therapy and prophylactic aspirin following total knee arthroplasty: a randomized control trial. J Arthroplasty. 2017;32(5):1478-1482.

64. Parvizi J, Huang R, Raphael IJ, Arnold WV, Rothman RH. Symptomatic pulmonary embolus after joint arthroplasty: Stratification of risk factors. Clin Orthop Relat Res. 2014;472(3):903-912.

65. Sculco PK, Pagnano MW. Perioperative solutions for rapid recovery joint arthroplasty: get ahead and stay ahead. J Arthroplasty. 2015;30(4):518-520.

66. Parameters P. Practice guidelines for preoperative fasting and the use of pharmacologic agents to reduce the risk of pulmonary aspiration. Anesthesiology. 2017;126(3):376-393.

67. Yilmaz N, Cekmen N, Bilgin F, Erten E, Ozhan MÖ, Coşar A. Preoperative carbohydrate nutrition reduces postoperative nausea and vomiting compared to preoperative fasting. J Res Med Sci. 2013;18(10):827-832.

68. Sukeik M, Alshryda S, Haddad FS, Mason JM. Systematic review and meta-analysis of the use of tranexamic acid in total hip replacement. J Bone Joint Surg Br. 2011;9393(1):39-46.

69. Poeran J, Rasul R, Suzuki S, et al. Tranexamic acid use and postoperative outcomes in patients undergoing total hip or knee arthroplasty in the United States: retrospective analysis of effectiveness and safety BMJ. 2014;349(aug12 8):g4829-g4829.

70. Jacobs CA, Christensen CP. Factors influencing patient satisfaction two to five years after primary total knee arthroplasty. J Arthroplasty. 2014;29(6):1189-1191.

71. Johnson RL, Kopp SL. Optimizing perioperative management of total joint arthroplasty. Anesthesiol Clin. 2014;32(4):865-880.

72. Webb CA, Mariano ER. Best multimodal analgesic protocol for total knee arthroplasty. Pain Manag. 2015;5(3):185-196.

73. Spangehl MJ, Clarke HD, Hentz JG, Misra L, Blocher JL, Seamans DP. The Chitranjan Ranawat Award: periarticular injections and femora \& sciatic blocks provide similar pain relief after TKA: a randomized clinical trial. Clin Orthop Relat Res. 2015;473(1):45-53.

74. Yu S, Szulc A, Walton S, Bosco J, Iorio R. Pain control and functional milestones in total knee arthroplasty: liposomal bupivacaine versus femoral nerve block. Clin Orthop Relat Res. 2017;475(1):110-117.

75. Yu SW, Szulc AL, Walton SL, Davidovitch RI, Bosco JA, Iorio R. Liposomal bupivacaine as an adjunct to postoperative pain control in total hip arthroplasty. J Arthroplasty. 2016;31(7):1510-1515.

76. Yu S, Dundon JM, Solovyova O, Bosco JA, Iorio R. Can multimodal pain management in total knee arthroplasty eliminate patient controlled analgesia and femoral nerve block. Clin Orthop Relat Res. In Press.

77. Fournier MN, Hallock J, Mihalko WM. Preoperative optimization of total joint arthroplasty surgical risk: obesity. J Arthroplasty. 2016;31(8):1620-1624.

78. Namba RS, Paxton L, Fithian DC, Stone ML. Obesity and perioperative morbidity in total hip and total knee arthroplasty patients. $J$ Arthroplasty. 2005;20(7 suppl 3):46-50.

79. Foran JR, Mont MA, Etienne G, Jones LC, Hungerford DS. The outcome of total knee arthroplasty in obese patients. J Bone Joint Surg Am. 2004;86-A(8):1609-1615.

80. Issa K, Pivec R, Kapadia BH, et al. Does obesity affect the outcomes of primary total knee arthroplasty? J Knee Surg. 2013;26(2):89-94.

81. Vazquez-Vela JG, Worland RL, Keenan J, Norambuena N. Patient demographics as a predictor of the ten-year survival rate in primary total knee replacement. J Bone Joint Surg Br. 2003;85(1):52-56.

82. Smith TO, Aboelmagd T, Hing CB, MacGregor A. Does bariatric surgery prior to total hip or knee arthroplasty reduce post-operative complications and improve clinical outcomes for obese patients? Systematic review and meta-analysis. Bone Joint J. 2016;98-B(9):1160-1166.

83. Callanan MC, Jarrett B, Bragdon CR, et al. The John Charnley Award: risk factors for cup malpositioning: quality improvement through a joint registry at a tertiary hospital. Clin Orthop Relat Res. 2011;469(2):319-329.
84. Kremers HM, Visscher SL, Kremers WK, Naessens JM, Lewallen DG. The effect of obesity on direct medical costs in total knee arthroplasty. J Bone Joint Surg Am. 2014;96(9):718-724.

85. Jevsevar DS, Brown GA, Jones DL, et al. The American Academy of Orthopaedic Surgeons evidence-based guideline on: treatment of osteoarthritis of the knee, 2nd edition. J Bone Joint Surg Am. 2013;95(20):1885-1886.

86. Springer BD, Carter JT, McLawhorn AS, et al. Obesity and the role of bariatric surgery in the surgical management of osteoarthritis of the hip and knee: a review of the literature. Surg Obes Relat Dis. 2017;13(1):111-118

87. Messier SP, Loeser RF, Mitchell MN, et al. Exercise and weight loss in obese older adults with knee osteoarthritis: a preliminary study. $J$ Am Geriatr Soc. 2000;48(9):1062-1072.

88. Gandler N, Simmance N, Keenan J, Choong PFM, Dowsey MM. A pilot study investigating dietetic weight loss interventions and 12 month functional outcomes of patients undergoing total joint replacement. Obes Res Clin Pract. 2016;10(2):220-223.

89. de Luis DA, Izaola O, García Alonso M, Aller R, Cabezas G, de la Fuente B. Effect of a commercial hypocaloric diet in weight loss and post surgical morbidities in obese patients with chronic arthropathy, a randomized clinical trial. Eur Rev Med Pharmacol Sci. 2012;16(13): 1814-1820.

90. Colquitt JL, Picot J, Loveman E, Clegg AJ. Surgery for obesity. Cochrane Database Syst Rev. 2009;2:CD003641.

91. Nearing EE, Santos TM, Topolski MS, Borgert AJ, Kallies KJ, Kothari SN. Benefits of bariatric surgery before elective total joint arthroplasty: is there a role for weight loss optimization? Surg Obes Relat Dis. 2017;13(3):457-462.

92. Groen VA, van de GraafVA, Scholtes VAB, Sprague S, van Wagensveld BA, Poolman RW. Effects of bariatric surgery for knee complaints in (morbidly) obese adult patients: a systematic review. Obes Rev. 2015;16(2):161-170.

93. Severson EP, Singh JA, Browne JA, Trousdale RT, Sarr MG, Lewallen DG. Total knee arthroplasty in morbidly obese patients treated with bariatric surgery. J Arthroplasty. 2012;27(9):1696-1700.

94. Martin JR, Watts CD, Taunton MJ. Bariatric surgery does not improve outcomes in patients undergoing primary total knee arthroplasty. Bone Joint J. 2015;97-B(11):1501-1505.

95. Dalcanale L, Oliveira CPMS, Faintuch J, et al. Long-term nutritional outcome after gastric bypass. Obes Surg. 2010;20(2):181-187.

96. Peterson LA, Cheskin LJ, Furtado M, et al. Malnutrition in bariatric surgery candidates: multiple micronutrient deficiencies prior to surgery. Obes Surg. 2016;26(4):833-838.

97. Walsh M, Woodhouse LJ, Thomas SG, Finch E. Physical impairments and functional limitations: a comparison of individuals 1 year after total knee arthroplasty with control subjects. Phys Ther. 1998;78(3): 248-258.

98. Moffet H, Collet JP, Shapiro SH, Paradis G, Marquis F, Roy L. Effectiveness of intensive rehabilitation on functional ability and quality of life after first total knee arthroplasty: a single-blind randomized controlled trial. Arch Phys Med Rehabil. 2004;85(4):546-556.

99. Petterson SC, Mizner RL, Stevens JE, et al. Improved function from progressive strengthening interventions after total knee arthroplasty: a randomized clinical trial with an imbedded prospective cohort. Arthritis Rheum. 2009;61(2):174-183.

100. Pozzi F, Snyder-Mackler L, Zeni J. Physical exercise after knee arthroplasty: a systematic review of controlled trials. Eur J Phys Rehabil Med. 2013;49(6):877-892.

101. Minns Lowe CJ, Barker KL, Dewey M, Sackley CM. Effectiveness of physiotherapy exercise after knee arthroplasty for osteoarthritis: systematic review and meta-analysis of randomised controlled trials. BMJ. 2007;335(7624):812.

102. Fransen M, Nairn L, Bridgett L, et al. Post-acute rehabilitation after total knee replacement: a multicenter randomized clinical trial comparing long-term outcomes. Arthritis Care Res (Hoboken). 2017;69(2):192-200. 
103. Russell TG, Buttrum P, Wootton R, Jull GA. Internet-based outpatient telerehabilitation for patients following total knee arthroplasty: a randomized controlled trial. J Bone Joint Surg Am. 2011;93(2):113-120.

104. Austin MS, Urbani BT, Fleischman AN, et al. Formal physical therapy after total hip arthroplasty is not required: a randomized controlled trial. J Bone Joint Surg Am. 2017;99(8):648-655.

105. Davidovitch R, Anoushiravani AA, Feng JE, et al. Home health services are not required following total hip arthroplasty. In: American Academy of Hip and Knee Surgeons Annual Meeting. Dallas, Texas. November 5, 2017.

106. Stacey D, Légaré F, Col Nananda F, et al. Decision aids for people facing health treatment or screening decisions. Cochrane Database Syst Rev. 2014;5(1):CD001431.

107. Baker A. Crossing the Quality Chasm: A New Health System for the 21st Century. Washington, DC: National Academies Press; 2001.

108. Andrawis J, Akhavan S, Chan V, Lehil M, Pong D, Bozic KJ. Higher preoperative patient activation associated with better patient-reported outcomes after total joint arthroplasty. Clin Orthop Relat Res. 2015;473(8):2688-2697.

109. Schaeffer JF, Scott DJ, Godin JA, Attarian DE, Wellman SS, Mather RC 3rd. The association of ASA class on total knee and total hip arthroplasty readmission rates in an academic hospital. J Arthroplasty. 2014;30(5):723-727.

110. Peersman G, Laskin R, Davis J, Peterson MGE, Richart T. ASA physical status classification is not a good predictor of infection for total knee replacement and is influenced by the presence of comorbidities. Acta Orthop Belg. 2008;74(3):360-364.

111. AJRR. American Joint Replacement Registry. 2014. Available from: http://www.ajrr.net/images/annual_reports/AJRR_2014_Annual_ Report_final_11-11-15.pdf. Accessed July 9, 2017.

112. Boraiah S, Joo L, Inneh IA, et al. Management of modifiable risk factors prior to primary hip and knee arthroplasty: a readmission risk assessment tool. J Bone Joint Surg. 2015;97(23):1921-1928.

113. Bozic KJ, Belkora J, Chan V, et al. Shared decision making in patients with osteoarthritis of the hip and knee results of a randomized controlled trial. J Bone Joint Surg Am. 2013;95(18):1633-1639.

114. Sepucha K, Freiberg AA, Mangla M, Malchau H, Rubash HE, Cha TD. Shared decision making in orthopaedic care leads to better health outcomes: a prospective cohort study. Annual Meeting of the American Academy of Orthopaedic Surgeons. San Diego, CA: American Academy of Orthopaedic Surgeons; 2017.

115. Stacey D, Hawker G, Dervin G, et al. Decision aid for patients considering total knee arthroplasty with preference report for surgeons: a pilot randomized controlled trial. BMC Musculoskelet Disord. 2014;15(1):54.

116. Ayers DC, Zheng H, Franklin PD. Integrating patient-reported outcomes into orthopaedic clinical practice: proof of concept from FORCE-TJR. Clin Orthop Relat Res. 2013;471(11):3419-3425.

117. Oshima Lee E, Emanuel EJ. Shared decision making to improve care and reduce costs. $N$ Engl J Med. 2013;368(1):6-8.

118. Arterburn D, Wellman R, Westbrook E, et al. Introducing decision aids at group health was linked to sharply lower hip and knee surgery rates and costs. Health Aff. 2012;31(9):2094-2104.

119. Mutran EJ, Reitzes DC, Mossey J, Fernandez ME. Social support, depression, and recovery of walking ability following hip fracture surgery. J Gerontol B Psychol Sci Soc Sci. 1995;50(6):S354-S361.

120. Lingard EA, Riddle DL. Impact of psychological distress on pain and function following knee arthroplasty. J Bone Joint Surg Am. 2007;89(6):1161-1169.

121. Riediger W, Doering S, Krismer M. Depression and somatisation influence the outcome of total hip replacement. Int Orthop. 2010;34(1):13-18.

122. Pacault-Legendre V, Anract P, Mathieu M, Courpied JP. Pain after total hip arthroplasty: a psychiatric point of view. Int Orthop. 2007;33(1):65-69.
123. Singh JA, Lewallen DG. Medical and psychological comorbidity predicts poor pain outcomes after total knee arthroplasty. Rheumatology (Oxford). 2013;52(5):916-923.

124. Gandhi R, Davey JR, Mahomed NN. Predicting patient dissatisfaction following joint replacement surgery. $J$ Rheumatol. 2008;35(12):2415-2418.

125. Lavernia CJ, Alcerro JC, Brooks LG, Rossi MD. Mental health and outcomes in primary total joint arthroplasty. $J$ Arthroplasty. 2012;27(7):1276-1282.

126. Rogers KD, Blyth FM, March LM, Jorm L. A nested case-control analysis of self-reported physical functioning after total knee replacement surgery in the 45 and up study cohort. BMJ Open. 2013;3(7):e002291.

127. Edwards RR, Haythornthwaite JA, Smith MT, Klick B, Katz JN. Catastrophizing and depressive symptoms as prospective predictors of outcomes following total knee replacement. Pain Res Manag. 2009;14(4):307-311.

128. Forsythe ME, Dunbar MJ, Hennigar AW, Sullivan MJ, Gross M. Prospective relation between catastrophizing and residual pain following knee arthroplasty: two-year follow-up. Pain Res Manag. 2008;13(4):335-341.

129. Riddle DL, Wade JB, Jiranek WA, Kong X. Preoperative pain catastrophizing predicts pain outcome after knee arthroplasty. Clin Orthop Relat Res. 2009;468(3):798-806.

130. Rubinsky AD, Sun H, Blough DK, et al. AUDIT-C alcohol screening results and postoperative inpatient health care use. J Am Coll Surg. 2012;214(3):296-305.e1.

131. Harris AHS, Reeder R, Ellerbe L, Bradley KA, Rubinsky AD, Giori NJ. Preoperative alcohol screening scores: association with complications in men undergoing total joint arthroplasty. J Bone Joint Surg Am. 2011;93(4):321-327.

132. Kim KY, Anoushiravani AA, Chen KK, Roof M, Long WJ, Schwarzkopf R. Preoperative chronic opioid users in total knee arthroplasty - which patients persistently abuse opiates following surgery? $J$ Arthroplasty. 2017;33(1):107-112.

133. Bush K, Kivlahan DR, McDonell MB, Fihn SD, Bradley KA. The AUDIT alcohol consumption questions (AUDIT-C) an effective brief screening test for problem drinking. Arch Intern Med. 1998;158(16):1789.

134. Skinner HA. DAST (drug abuse screening test). Addict Behav. 1982;7:363-371.

135. Kroenke K, Spitzer RL, Williams JBW. The patient health questionnaire- 2 validity of a two-item depression screener. Med Care. 2003;41(11):1284-1292.

136. Spitzer RL, Kroenke K, Williams JBW, Löwe B. A brief measure for assessing generalized anxiety disorder. Arch Intern Med. 2006;166(10):1092.

137. Foster NE, Delitto A. Embedding psychosocial perspectives within clinical management of low back pain: integration of psychosocially informed management principles into physical therapist practice challenges and opportunities. Phys Ther. 2011;91(5):790-803.

138. Keefe FJ, Beaupre PM, Gil KM. Group therapy for patients with chronic pain. In: Turk DC, Gatchel RJ, editors. Psychol Approaches to Pain Manag A Pract Handb. New York: Guilford Press; 1996:259-282.

139. Turk D, Meichenbaum D, Genest M, Berntzen D. Pain and behavioral medicine: a cognitive-behavioral perspective. Scand J Behav Ther. 1984;13(4):243-244.

140. Wieser K, Zingg PO, Betz M, Neubauer G, Dora C. Total hip replacement in patients with history of illicit injecting drug use. Arch Orthop Trauma Surg. 2012;132(7):1037-1044.

141. Grotle M, Garratt AM, Klokkerud M, Lochting I, Uhlig T, Hagen KB. What's in team rehabilitation care after arthroplasty for osteoarthritis? Results from a multicenter, longitudinal study assessing structure, process, and outcome. Phys Ther. 2010;90(1):121-131. 


\section{Publish your work in this journal}

The Journal of Multidisciplinary Healthcare is an international, peerreviewed open-access journal that aims to represent and publish research in healthcare areas delivered by practitioners of different disciplines. This includes studies and reviews conducted by multidisciplinary teams as well as research which evaluates the results or conduct of such teams or health care processes in general. The journal covers a very wide range of areas and welcomes submissions from practitioners at all levels, from all over the world The manuscript management system is completely online and includes a very quick and fair peer-review system. Visit http://www.dovepress.com/ testimonials.php to read real quotes from published authors.

Submit your manuscript here: https://www.dovepress.com/journal-of-multidisciplinary-healthcare-journal 